\title{
PENGARUH PERAWATAN METODE KANGURU TERHADAP KENAIKAN BERAT BADAN PADA BAYI BERAT BADAN LAHIR RENDAH DI RUANG PERINATOLOGI RSUD DR. RASIDIN PADANG TAHUN 2017
}

\author{
Mardiani Bebasari ${ }^{1}$, Agonwardi ${ }^{2}$, \\ Nandiati ${ }^{3}{ }^{1}$ Dosen Jurusan Kebidanan \\ Poltekkes Kemenkes Padang Email: \\ mardiani_pdg@yahoo.com \\ ${ }^{2}$ Dosen Jurusan Kebidanan Poltekkes \\ Kemenkes Padang Email: \\ agonwardinasution@yahoo.com \\ 3 Prodi DIV Kebidanan Poltekkes Kemenkes \\ Padang \\ Email : nandiatiafriza@gmail.com
}

\begin{abstract}
ABSTRAK
Berdasarkan data rekam medis RSUD Dr. Rasidin Padang pada tahun 2014 bayi yang lahir dengan BBLR adalah 43 bayi, pada 2015 berjumlah 48 bayi. Sedangkan pada 2016 adalah 53 bayi. Bayi dengan BBLR tidak semuanya menerima layanan kesehatan dengan teknologi canggih karena hambatan biaya, geografis, transportasi, dan komunikasi. Pengganti inkubator adalah alternatif yang efektif dan ekonomis, salah satunya adalah pengobatan metode kanguru. Penelitian ini bertujuan untuk mengetahui pengaruh metode kanguru terhadap penambahan berat badan pada bayi dengan berat lahir rendah.

Jenis penelitian ini menggunakan Quasy Experiment. Data yang dikumpulkan dengan menggunakan pengamatan langsung dengan metode penelitian analitik, teknik sampling menggunakan purposive sampling. Penelitian dilakukan pada tanggal 19 desember s/d 12 Juni 2017, populasinya adalah semua ibu yang memiliki bayi BBLR di ruang Perinatologi RSUD Dr Rasidin berjumlah 15 orang. Pengumpulan data dilakukan dengan cara observasi menggunakan lembar cheklist. Pengolahan data melalui tahap editing, coding, entry dan cleaning. Analisis data univariat dengan statistik deskriptif dan analisis bivariat dengan Paired T-Test.

Hasil penelitian menunjukkan bahwa rata-rata berat BBLR bayi sebelum perlakuan metode kangguru adalah 1871,33 gram dan setelah perlakuan metode kangguru adalah 2135,33 gram. Ada pengaruh pengobatan metode kanguru terhadap kenaikan berat badan pada bayi BBLR di Ruang Perinatologi RSUD Dr. Rasidin Padang Tahun 2017. Penelitian ini dapat digunakan sebagai bahan bidan untuk mengetahui manfaat metode kangguru, sehingga dapat diimplementasikan pada kebidanan. perawatan pada bayi BBLR. Pengobatan metode kanguru yang telah dilakukan di RSUD Dr. Rasidin Padang, dapat digunakan sebagai perawatan rutin yang dilakukan pada bayi BBLR jika kondisi bayi memungkinkan untuk pengobatan metode kanguru.
\end{abstract}

Kata kunci: weigth, kanguru metode perawatan

ABSTRACT

Medical record data of RSUD Dr. Rasidin Padang in 2014 babies born with LBW is 43 babies, in 2015 amounted to 48 babies. While in 2016 is 53 babies. Infants with LBW do not all receive health services with advanced technology due to cost, geographical, transport, and communications barriers. Substitutes for incubators are an effective and economical alternative, one of which is the treatment of kangaroo methods. This study aims to determine the effect of kangaroo method on weight gain in low birth weight babies.

This type of research uses Quasy Experiment. The data collected by using direct observation with analytical research method, sampling technique by purposive sampling. The study was conducted on 19 december s / d 12 June 2017, the population is all mothers who have baby BBLR dirinatologi Perinatologi RSUD Dr. Rasidin Padang Sampling technique is accidental sampling amounted to 15 people. Data collection is done by observation using cheklist sheet. Data processing through the stage of editing, coding, entry and cleaning. Univariate data analysis with descriptive statistics and bivariate analysis with Paired T-Test.

The results showed that the average body weight of infant BBLR before treatment of kangaroo method was 1871,33 and after treatment of kangaroo method was 2135,33 gram. There is effect of treatment of kangaroo method on weight gain in LBW infants in Perinatology Room of RSUD Dr. Rasidin Padang Year 2017. This research can be used as an ingredient for midwives about the benefits of kangaroo method, so it can be implemented in midwifery care in LBW infants. Treatment of kangaroo method that has been done in RSUD Dr. Rasidin Padang, can be used as a routine care done to babies LBW if the condition of the baby allows for treatment of kangaroo methods.

Keywords: weigth, kangaroo method care 


\section{PENDAHULUAN}

Prevalensi Berat Badan Lahir Rendah $(B B L R)$ di perkirakan $15 \%$ dari seluruh kelahiran di dunia dengan batasan 3,3\%- 38\% dan lebih sering terjadi di negara- negara berkembang atau sosioekonomi rendah. Secara statistik menunjukkan $90 \%$ kejadian BBLR didapatkan di negara berkembang dan angka kematiannya 35 kali lebih tinggi di banding pada bayi dengan berat lahir lebih dari 2500 gram (Profil Kesehatan Indonesia, 2013). BBLR termasuk faktor utama dalam peningkatan mortalitas, morbiditas dan disabilitas neonatus, bayi dan anak serta memberikan dampak jangka panjang terhadap kehidupannya di masa depan (WHO).

Angka kejadian BBLR di Indonesia sangat bervariasi antara satu daerah dengan daerah lain, yaitu berkisar antara 9\%-30\%, hasil studi di daerah multicenter diperoleh angka BBLR dengan rentang 2,1\%-17,2\%. Secara nasional berdasarkan analisa lanjut SDKI, angka kejadian BBLR sekitar 7,5\%. Angka ini lebih besar dari target BBLR yang ditetapkan pada sasaran program.

Kejadian BBLR di Sumatera Barat tahun 2015 adalah sebanyak 1420 kasus dan bayi meninggal yang disebabkan oleh BBLR adalah sebesar 283 kasus (Dinkes Sumber, 2015). Berdasarkan data dari Dinas Kesehatan Kota (DKK) Padang tahun 2015 diperoleh data kejadian BBLR adalah sebanyak 171 kasus dari 17.767 kelahiran hidup, ini mengalami peningkatan dari tahun 2014. Dimana tahun 2014 hanya 94 bayi yang mengalami BBLR (DKK, 2015).

Data dari dinas kesehatan Propinsi Sumatra Barat tahun 2012 menunjukkan cakupan neonatus dengan komplikasi yang ditangani oleh tenaga kesehatan yang terlatih sesuai standar disuatu wilayah kerja pada kurun waktu tertentu. Dari target yang ditetapkan $72 \%$ yang tercapai hanya $12 \%$ angka ini sedikit meningkat dari 2011 (11\%), ini semua di sebabkan oleh minimnya sumber daya manusia dan dana untuk mempertahankan dan memperluas upaya-upaya interfensi seperti manajemen Asfiksia, BBLR, manajemen terpadu bayi muda, pemberdayaan masyarakat, pemberdayaan melalui buku KIA, sistem rujukkan neonatal komplikasi belum berjalan optimal.

Data rekam medik RSUD Dr. Rasidin Padang pada tahun 2014 bayi yang terlahir dengan BBLR adalah 43 bayi, pada tahun 2015 terjadinya peningkatan BBLR yang berjumlah 48 bayi dari keseluruhan bayi baru lahir. Sedangkan pada tahun 2016 kembali meningkat menjadi 53 bayi. BBLR adalah bayi baru lahir yang berat badannya saat lahir kurang dari 2500 gram. Penatalaksanaan umum pada bayi BBLR yaitu mempertahankan suhu tubuh, pengaturan dan pengawasan intake nutrisi, pencegahan infeksi, penimbangan berat badan, pemberian oksigen dan pengawasan jalan nafas (Ismawati, 2010).

Bayi BBLR sangat cepat kehilangan panas tubuh, hal ini disebabkan ketidakmampuan untuk mempertahankan panas dan kesanggupan menambah produksi panas sangat terbatas karena pertumbuhan otot-otot yang belum cukup memadai, lemak subkutan yang sedikit, belum matangnya system syaraf pengatur suhu tubuh, luas permukaan tubuh relative lebih besar di bandingkan dengan berat badan sehingga masalah kehilangan panas (IDAI, 2015).

BBLR berakibat jangka panjang terhadap tumbuh kembang anak di masa yang akan datang. Dampak dari bayi dengan BBLR ini adalah pertumbuhannya akan lambat, kecendrungan memiliki penampilan intelektual yang lebih rendah daripada bayi yang berat lahirnya normal. Selain itu bayi BBLR dapat mengalami gangguan mental dan fisik pada usia tumbuh kembang selanjutnya sehingga membutuhkan biaya perawatan yang tinggi (IDAI, 2015)

Bayi dengan BBLR tidak semuanya mendapatkan pelayanan kesehatan dengan teknologi maju karena hambatan biaya, geografis, transportasi, dan komunikasi. Pengganti inkubator diperlukan cara alternatif yang efektif dan ekonomis. Pelaksanaan perawatan metoda kanguru adalah satu upaya yang dilakukan untuk mengatasi berbagai permasalahan pada bayi dengan berat badan lahir rendah. Perawatan Metode Kanguru merupakan suatu cara khusus dalam merawat bayi berat badan lahir rendah. Perawatan ini dengan cara melakukan kontak langsung antara kulit bayi dengan kulit ibu. Kontak langsung ini berguna untuk membantu perkembangan kesehatan bayi melalui peningkatan kontrol suhu, menyusui, pencegahan infeksi, dan kontak ibu dengan bayi yang dimulai di tempat perawatan diteruskan di rumah, dikombinasi dengan pemberian air susu ibu yang bertujuan agar bayi tetap hangat.

Perawatan BBLR sifatnya sangat kompleks. Pada umumnya berat badan lahir rendah dirawat dalam inkubator. Bayi perlu dirawat di inkubator dengan biaya perawatan yang cukup tinggi, dan membutuhkan tenaga kesehatan yang berpengalaman. Jumlah inkubator di rumah sakit sangat terbatas dibadanding dengan jumlah BBLR yang dirawat. Beberapa penelitian telah dilakukan tentang metode kanguru, hasilnya mengatakan bahwa metode kanguru tidak hanya sekedar pengganti inkubator dalam perawatan BBLR, namun juga 
memberi banyak keuntungan yang tidak bisa diberikan oleh perawatan incubator (IDAI, 2015).

Perawatan metode kanguru bermanfaat dalam menstabilkan suhu tubuh bayi, stabilitas denyut jantung dan pernafasan, perilaku bayi lebih baik, kurang menangis dan sering menyusu, penggunaan kalori berkurang, kenaikan berat badan bayi lebih baik, waktu tidur bayi lebih lama, hubungan lekat bayi- ibu lebih baik dan akan mengurangi terjadinya infeksi pada bayi. Metode Kanguru adalah metode perawatan dini dengan sentuhan kulit ke kulit antara ibu dan bayi baru lahir dalam posisi seperti kanguru. Dengan metode ini mampu memenuhi kebutuhan asasi bayi baru lahir prematur dengan menyediakan situasi dan kondisi yang mirip dengan rahim ibu. Sehingga memberi peluang untuk dapat beradaptasi baik dengan dunia luar. Perawatan kanguru ini telah terbukti dapat menghasilkan pengaturan suhu tubuh yang efektif dan lama serta denyut jantung dan pernafasan yang stabil pada bayi. Perawatan kulit ke kulit mendorong bayi untuk mencari puting dan mengisapnya, hal ini mempererat ikatan antara ibu dan bayi serta membantu keberhasilan pemberian ASI. Di samping efek sentuhan kulit, metode tersebut akan membuat bayi lebih tahan sakit daripada dengan digendong memakai jarit. Berat badannya pun akan cepat naik (Dyah, 2013).

Penelitian sebelumnya yang dilakukan oleh Dyah Puji Astuti (2013) tentang pengaruh penerapan metode kanguru dengan peningkatan berat badan bayi baru lahir rendah (BBLR) di rumah sakit PKU Muhammadiyah Gombang, menemukan bahwa terdapat perbedaan yang signifikan berat badan pada bayi yang diberikan perlakuan metode kanguru yaitu dan yang tidak diberikan perlakuan metode kanguru, dibuktikan dengan nilai $\mathrm{t}$ hitung $>\mathrm{t}$ table, dan nilai $\mathrm{p}<0,05$.

Berdasarkan survey awal dengan mengamati 5 orang ibu yang mempunyai bayi dengan berat badan lahir rendah dengan perawatan metode kanguru didapatkan 3 orang mengalami kenaikan berat badan dari 2400 gram menjadi 2500 gram setelah melakukan perawatan kanguru selama 5 hari. Sedangkan 2 orang lagi tidak mengalami kenaikan yaitu dengan berat badan 2450 gram.

Berdasarkan dengan hal diatas penulis tertarik untuk melakukan penelitian tentang pengaruh perawatan metode kanguru terhadap kenaikan berat badan pada bayi berat badan lahir rendah di Ruang Perinatologi RSUD Dr. Rasidin Padang Tahun 2017.

\section{METODE PENELITIAN}

Penelitian ini menggunakan metode pre experimental design dengan jenis pre test and post test one group design. Metode ini diberikan pada satu kelompok saja tanpa kelompok pembanding. Desain penelitian yang digunakan kuantitatif dengan pre dan post test without control (kontrol diri sendiri) karena pada desain penelitian ini peneliti hanya melakukan intervensi pada suatu kelompok tanpa pembanding. Kelompok subjek diobservasi sebelum dilakukan intervensi kemudian diobservasi lagi setelah intervensi. Penelitian ini telah dilaksanakan di Ruang Perinatologi RSUD Dr.Rasidin Padang yang dilakukan pada bulan 21 April s/d 28 Mei 2017. Populasi dari penelitian ini adalah bayi BBLR di Ruang Perinatologi RSUD Dr. Rasidin Padang pada bulan Mei 2017. Pengambilan sampel pada penelitian ini menggunakan metode accidental sampling. Data dikumpulkan dengan menggunakan kuesioner terstruktur dan observasi langsung. Analisis yang digunakan adalah analisis univariat dengan distribusi frekuensi dan analisis bivariat dengan uji Paired T-Test.

\section{HASIL PENELITIAN}

\section{A. Gambaran Umum Penelitian}

Penelitian ini dilakukan di ruang Perinatologi RSUD Dr. Rasidin Padang. Sakit ini memiliki karakteristik yaitu rumah sakit tipe $\mathrm{C}$ yang menyediakan pelayanan untuk bayi dengan resiko tinggi termasuk BBLR, dengan dua orang dokter spesialis anak dan merupakan rumah sakit rujukan. Penelitian ini dilakukan dari bulan 19 Desember 2016 s/d 12 Juni 2017.

Sampel penelitian ini adalah BBLR yang berjumlah 15 BBLR untuk perawatan metode kanguru di RSUD Dr. Rasidin Padang yang dipilih secara accidental sesuai kriteria inklusi. Selama melakukan penelitian tidak ada responden yang mengalami drop out. Masing-masing intervensi dilakukan selama 6 hari. Sebelum dilakukan intervensi responden dilakukan pengukuran berat badan (pretest), posttest dilakukan 24 jam setelah intervensi hari ke-6.

\section{B. Hasil Penelitian \\ 1. Analisis Univariat \\ a. Rerata Berat Badan pada Bayi BBLR Sebelum Perawatan Metode Kanguru \\ Tabel 1 Rerata Berat Badan pada Bayi BBLR Sebelum Perawatan Metode Kanguru di Ruang Perinatologi RSUD Dr. Rasidin Padang Tahun 2017}

Mean Median Min Max SD




$$
\begin{array}{lllll}
1871,33 & 1860,00 & 1650 & 2000 & 97,311
\end{array}
$$

Berdasarkan tabel 1 diatas dapat dilihat bahwa rata-rata berat badan bayi BBLR sebelum perawatan metode kanguru adalah 1871,33 gram dengan nilai median sebesar 1860 gram. Berat badan bayi BBLR paling rendah adalah 1650 gram dan tertinggi adalah 2000 gram dengan nilai standar deviasi 97,311 gram.

\section{Rerata Berat Badan pada Bayi BBLR Sesudah Perawatan Metode Kanguru}

\section{Tabel 2 Rerata Berat Badan pada Bayi BBLR}

Sesudah Perawatan Metode Kanguru di Ruang Perinatologi RSUD Dr. Rasidin Padang Tahun 2017

\begin{tabular}{ccccc}
\hline Mean & Median & Min & Max & SD \\
\hline 2108,67 & 2120,00 & 1890 & 2270 & 107,096 \\
\hline
\end{tabular}

Berdasarkan tabel 2 diatas dapat dilihat bahwa rata-rata berat badan bayi BBLR sesudah perawatan metode kanguru adalah 2108,67 gram dengan nilai median sebesar 1890 gram. Berat badan bayi BBLR paling rendah adalah 1890 gram dan tertinggi adalah 2270 gram dengan nilai standar deviasi 107,096 gram.

\section{Analisis Bivariat}

Tabel 3 Pengaruh Perawatan Metode Kanguru Terhadap Kenaikan Berat Badan Pada Bayi BBLR di Ruang Perinatologi RSUD Dr. Rasidin Padang Tahun 2017

\begin{tabular}{cccccc}
\hline Kelompok & $\mathbf{n}$ & $\boldsymbol{X}$ & + SD & t & P value \\
& & & & \\
\hline Sebelum & 15 & 44,796 & $-20,519$ & 0,000 \\
\hline Sesudah & 15 & & & \\
\hline
\end{tabular}

Berdasarkan tabel 3 diatas dapat dilihat bahwa perbedaan standar deviasi berat badan sebelum dan sesudah melakukan perawatan metode kanguru adalah sebesar 44,796. Berdasarkan Nilai t hitung didapatkan sebesar 20,519 dengan nilai $\mathrm{p}=$ 0,000. Karena $\mathrm{p}<0,05$ maka dapat disimpulkan bahwa Ho ditolak, artinya adanya pengaruh perawatan metode kanguru terhadap kenaikan berat badan pada bayi BBLR di Ruang Perinatologi RSUD Dr. Rasidin Padang Tahun 2017.

\section{PEMBAHASAN}

\section{Analisa Univariat}

a. Rerata Berat Badan pada Bayi BBLR Sebelum Perawatan Metode Kanguru

Berdasarkan hasil penelitian didapatkan bahwa rata-rata berat badan bayi BBLR sebelum perawatan metode kanguru adalah 1871,33 gram dengan nilai median sebesar 1860 gram. Berat badan bayi BBLR paling rendah adalah 1650 gram dan tertinggi adalah 2000 gram dengan nilai standar deviasi 97,311 gram. Hasil penelitian ini sejalan dengan penelitian sebelumnya yang dilakukan oleh Dyah Puji Astuti (2013) tentang pengaruh penerapan metode kanguru dengan peningkatan berat badan bayi baru lahir rendah (BBLR) di rumah sakit PKU Muhammadiyah Gombang, menemukan bahwa ratarata berat badan sebelum perawatan kanguru adalah sebesar 1950 gram.

Pada bayi BBLR yang harus dilakukan tindakkan penanganan di rumah sakit, juga tergantung pada kondisi bayi masing-masing. Namun tindakkan yang dilakukan oleh tim medis pada bayi yang dilahirkan dengan BBLR akan segera di periksa fungsi organ-organ tubuhnya terutama paru-paru dan jantung. Sebelum mencapai berat yang cukup, bayi BBLR biasanya memerlukan perawatan intensif terhadap perubahan suhu. Pemberian alat bantu pernafasan juga dilakukan bila terdapat indikasi. Untuk indikasi ringan, bayi hanya akan diberi oksigen. Sebaliknya jika berat dapat sampai diberi ventilator atau alat bantu pernafasan. Infus juga akan diberikan untuk masukan cairan dan obat- obatan bila diperlukan. Bayi-bayi kecil biasanya belum mampu mengisap dengan baik karena itu bila ASI ibu belum keluar dilakukan melalui pipa lambung_dan diberikan secara bertahap sampai jumlah kebutuhannya terpenuhi (Rukiyah, 2010).

Tidak ada patokan pasti untuk lama perawatan bayi BBLR di rumah sakit. Bayi dengan berat 1.000 gram, misalnya, memerlukan perawatan seksama dan bertahap sehingga bisa satu bulan lebih harus berada dalam inkubator. Lama perawatan lebih ditentukan oleh kemampuan bayi beradaptasi dengan lingkungan, seperti tidak ada lagi gangguan pernafasan, suhu tubuh telah stabil dan bayi sudah punya refleks isap dan menelan yang baik. Sebelum pulang, bayi sudah mampu minum sendiri dengan botol maupun 
dengan putting susu ibu. Selain itu kenaikan berat badannya telah berkisar 10- 30 gram/hari dan suhu tubuh tetap normal diruangan biasa. Bayi juga tidak menderita gangguan pernafasan lagi dan tidak membutuhkan oksigen serta obat-obatan yang diberikan melalui pembuluh darah atau infus (Rukiyah, 2010).

Dampak jangka panjang terhadap tumbuh kembang anak di masa yang akan datang. Dampak dari bayi dengan BBLR ini adalah pertumbuhannya akan lambat, kecendrungan memiliki penampilan intelektual yang lebih rendah daripada bayi yang berat lahirnya normal. Selain itu bayi BBLR dapat mengalami gangguan mental dan fisik pada usia tumbuh kembang selanjutnya sehingga membutuhkan biaya perawatan yang tinggi. 7 Bayi dengan BBLR tidak semuanya mendapatkan pelayanan kesehatan dengan teknologi maju karena hambatan biaya, geografis, transportasi, dan komunikasi. Pengganti inkubator diperlukan cara alternatif yang efektif dan ekonomis. Pelaksanaan perawatan metoda kanguru adalah satu upaya yang dilakukan untuk mengatasi berbagai permasalahan pada bayi dengan berat badan lahir rendah. Perawatan Metode Kanguru merupakan suatu cara khusus dalam merawat bayi berat badan lahir rendah. Perawatan ini dengan cara melakukan kontak langsung antara kulit bayi dengan kulit ibu. Kontak langsung ini berguna untuk membantu perkembangan kesehatan bayi melalui peningkatan kontrol suhu, menyusui, pencegahan infeksi, dan kontak ibu dengan bayi yang dimulai di tempat perawatan diteruskan di rumah, dikombinasi dengan pemberian air susu ibu yang bertujuan agar bayi tetap hangat.

\section{b. Rerata Berat Badan pada Bayi BBLR Sesudah Perawatan Metode Kanguru}

Berdasarkan hasil penelitian didapatkan bahwa ratarata berat badan bayi BBLR sesudah perawatan metode kanguru adalah 2108,67 gram dengan nilai median sebesar 1890 gram. Berat badan bayi BBLR paling rendah adalah 1890 gram dan tertinggi adalah 2270 gram dengan nilai standar deviasi 107,096 gram.

Hasil penelitian ini sejalan dengan penelitian sebelumnya yang dilakukan oleh Dyah Puji Astuti (2013) tentang pengaruh penerapan metode kanguru dengan peningkatan berat badan bayi baru lahir rendah (BBLR) di rumah sakit PKU Muhammadiyah Gombang, menemukan bahwa rata-rata berat badan sesudah perawatan kanguru adalah sebesar 2250 gram. Perawatan metode kanguru bermanfaat dalam menstabilkan suhu tubuh bayi, stabilitas denyut jantung dan pernafasan, perilaku bayi lebih baik, kurang menangis dan sering menyusu, penggunaan kalori berkurang, kenaikan berat badan bayi lebih baik, waktu tidur bayi lebih lama, hubungan lekat bayi- ibu lebih baik dan akan mengurangi terjadinya infeksi pada bayi. Metode Kanguru adalah metode perawatan dini dengan sentuhan kulit ke kulit antara ibu dan bayi baru lahir dalam posisi seperti kanguru. Dengan metode ini mampu memenuhi kebutuhan asi bayi baru lahir prematur dengan menyediakan situasi dan kondisi yang mirip dengan rahim ibu. Sehingga memberi peluang untuk dapat beradaptasi baik dengan dunia luar.

Perawatan kanguru ini telah terbukti dapat menghasilkan pengaturan suhu tubuh yang efektif dan lama serta denyut jantung dan pernafasan yang stabil pada bayi. Perawatan kulit ke kulit mendorong bayi untuk mencari puting dan mengisapnya, hal ini mempererat ikatan antara ibu dan bayi serta membantu keberhasilan pemberian ASI. Di sampingefek sentuhan kulit, metode tersebut akan membuat bayi lebih tahan sakit daripada dengan digendong memakai jarit dan berat badannya pun akan cepat naik (Diyah, 2013).

Hasil penelitian ini membuktikan keefektifan metode kanguru untuk meningkatkan berat badan bayi dengan BBLR. Berdasarkan kerangka konsep penelitian, penerapan metode kanguru dapat meningkatkan berat badan bayi secara optimal. Hal ini dikarenakan seorang bayi lahir dengan bayi berat lahir rendah (BBLR), umumnya akan diletakkan ke dalam inkubator agar suhu tubuhnya tetap normal serta diberi bantuan oksigen untuk pernafasan dan bayi berat lahir rendah (BBLR) juga dapat mengalami gangguan mental dan fisik pada usia tumbuh kembang selanjutnya, sehingga dalam perawatannya membutuhkan biaya perawatan yang tinggi, selain inkubator suhu tubuh bayi dapat dipertahankan kehangatannya dengan metode kanguru. Dulu metode ini dianggap hanya untuk orang miskin karena kalau orang kaya diletakkan di inkubator, tapi berdasarkan pengalaman, hasilnya malah lebih efektif metode kanguru (Marni, 2012).

Selain itu, pada metode kanguru risiko bayi mendapat infeksi lebih kecil, karena flora normal kulit ibu tentu lebih baik daripada yang tidak menggunakan metode kanguru. Lebih lanjut pada bayi baru lahir yang sakit atau kecil (berat lahir < 2500 gram), membutuhkan penambahan kehangatan tubuh untuk mempertahankan suhu normal. Bayi berat badan rendah dapat dengan cepat terjadi hipotermi dan untuk menghangatkan kembali embutuhkan waktu yang lama. Risiko komplikasi dan kematian meningkat secara bermakna bila suhu lingkungan tidak optimal. Menurut Departemen Kesehatan RI (2003) ada lima cara menghangatkan dan mempertahankan suhu tubuh pada bayi berat lahir rendah salah satunya adalah dengan metode kanguru (Ika, 2010).

\section{Analisa Bivariat}




\section{a. Pengaruh Perawatan Metode Kanguru Terhadap Kenaikan Berat Badan Pada Bayi BBLR}

Berdasarkan hasil penelitian didapatkan bahwa perbedaan standar deviasi berat badan sebelum dan sesudah melakukan perawatan metode kanguru adalah sebesar 44,796. Berdasarkan Nilai t hitung didapatkan sebesar 20,519 dengan nilai $\mathrm{p}=$ 0,000 . Karena $\mathrm{p}<0,05$ maka dapat disimpulkan bahwa adanya pengaruh

perawatan metode kanguru terhadap kenaikan berat badan pada bayi BBLR di Ruang Perinatologi RSUD Dr. Rasidin Padang Tahun 2017.

Hasil penelitian yang dilakukan oleh Dyah, dkk (2013) membuktikan keefektifan metode kanguru untuk meningkatkan berat badan bayi dengan BBLR. Berdasarkan kerangka konsep penelitian, penerapan metode kanguru dapat meningkatkan berat badan bayi secara optimal. Hal ini dikarenakan seorang bayi lahir dengan bayi berat lahir rendah (BBLR), umumnya akan diletakkan ke dalam inkubator agar suhu tubuhnya tetap normal serta diberi bantuan oksigen untuk pernafasan dan bayi berat lahir rendah (BBLR) juga dapat mengalami gangguan mental dan fisik pada usia tumbuh kembang selanjutnya, sehingga dalam perawatannya membutuhkan biaya perawatan yang tinggi, selain inkubator suhu tubuh bayi dapat dipertahankan kehangatannya dengan metode kanguru.

Dulu metode ini dianggap hanya untuk orang miskin karena kalau orang kaya diletakkan di inkubator, tapi berdasarkan pengalaman, hasilnya malah lebih efektif metode kanguru. Metode kanguru dapat menstabilkan detak jantung bayi dan pernapasannya lebih teratur, sehingga penyebaran oksigen ke seluruh tubuhnya pun lebih baik. Selain itu, cara ini mencegah bayi kedinginan. Bayi lebih tenang, lebih jarang menangis, dan kenaikan berat badannya menjadi lebih cepat (Ika, 2010).

Berat badan merupakan ukuran antropometri yang terpenting dan paling sering digunakan pada bayi baru lahir (neonatus). Pada masa bayi-balita, berat badan dapat digunakan untuk melihat laju pertumbuhan fisik maupun status gizi. Pertumbuhan sebagai suatu peningkatan dalam ukuran fisik tubuh secara keseluruhan atau sebagai peningkatan dalam setiap bagianya, berkaitan dengan suatu peningkatan dalam jumlah atau ukuran sel. Bayi yang lahir cukup bulan, berat badan waktu lahir akan kembali pada hari ke-10. Pertambahan berat rata-rata bayi selama 3 bulan pertama sekitar 200 gr/minggu, pada 3 bulan kedua $150 \mathrm{~g} / \mathrm{minggu}$ dan pada tahun kedua $42 \mathrm{~g} /$ minggu (Ika, 2010).

Rata-rata peningkatan metode kanguru berdasarkan uji statistik dinyatakan signifikan, hal ini berarti metode kanguru dapat dijadikan rekomendasi bagi orang tua, pelayanan kesehatan untuk menangani masalah BBLR dengan menerapkan metode kanguru dirumah. Selain itu dalam penelitian ini penerapan metode kanguru dilakukan hanya 60 menit/hari, hal itu saja mampu meningkatkan berat badan bayi lebih tinggi dibandingkan dengan bayi yang tidak diterapkan metode kanguru, apalagi bila diterapkan metode ini selama 24 jam/harinya (Diyah, 2013).

Adanya pengaruh perawatan metode kanguru dan kenaikan berat badan pada BBLR karena bayi dalam keadaan rileks, beristirahat dengan posisi yang menyenangkan, menyerupai posisi dalam rahim, sehingga kegelisahan bayi berkurang dan tidur lebih lama. Pada keadaan tersebut konsumsi oksigen dan kalori berada pada tingkat paling rendah, sehingga kalori yang ada digunakan untuk menaikkan berat badan. Selain itu juga dengan perawatan metode kanguru, produksi ASI menjadi meningkat dan frekuensi menyusu jadi lebih sering, sehingga efek pada peningkatan berat badan jadi lebih baik (Suradi, 2000). Teori tersebut senada dengan kondisi di lapangan setelah ibu melakukan PMK produksi ASI ibu meningkat terlihat adanya rembesan ASI pada kain yang digunakan sehingga ibu menggunakan kain untuk mencegah rembesan ASI membasahi tubuh bayi.

\section{KESIMPULAN DAN SARAN}

\section{a. Kesimpulan}

Rata-rata berat badan bayi BBLR sebelum perawatan metode kanguru adalah 1871,33 gram dengan nilai median sebesar 1860 gram. Berat badan bayi BBLR paling rendah adalah 1650 gram dan tertinggi adalah 2000 gram dengan nilai standar deviasi 97,311 gram. Rata-rata berat badan bayi BBLR sesudah perawatan metode kanguru adalah 2135,33 gram dengan nilai median sebesar 1890 gram. Berat badan bayi BBLR paling rendah adalah 1890 gram dan tertinggi adalah 2340 gram dengan nilai standar deviasi 127,888 gram. Terdapat pengaruh perawatan metode kanguru terhadap kenaikan berat badan pada bayi BBLR di Ruang Perinatologi RSUD Dr. Rasidin Padang Tahun 2017.

\section{b. Saran}

Perawatan metode kanguru yang selama ini dilakukan di RSUD Dr. Rasidin Padang, bisa dijadikan sebagai tindakan yang rutin dilakukan kepada bayi BBLR bila kondisi bayi memungkinkan untuk dilakukan perawatan metode kanguru.

\section{DAFTAR PUSTAKA}

1. Profil Kesehatan Indonesia, 2013. Target penurunan AKB pada MDG 2015 
2. WHO. Angka BBLR di Dunia. Diakses dari http://www.who-angka-bblrdidunia.com

3. Kemenkes RI, 2014. Riskesdas tahun 2013 : BBLR. Jakarta.

4. Dinkes Sumbar, 2015. Profil Kesehatan Propinsi Sumatera Barat. Padang : Dinkes.

5. Dinas Kesehatan Kota Padang, 2015. Propil Kesehatan Kota Padang. Padang ; Dinkes.

6. Ismawati, Proverawati, 2010. BBLR : Berat Badan Lahir Rendah. Yogyakarta: Nuha Medika.

7. IDAI, 2015. Ikatan Dokter Anak Indonesia. Jakarta.

8. Dyah Puji Astuti, 2013. Pengaruh penerapan metode kanguru dengan peningkatan berat badan bayi baru lahir rendah (BBLR) di rumah sakit PKU Muhammadiyah Gombang. http://www.01- gdl-dyahpujiastuti-1309-1kti-anis-8(2).pdf

9. Ika, 2010. Bayi Berat Badan Lahir Rendah. Dalam : Standar Pelayanan Medis

Kesehatan Anak. Edisi I. Jakarta
10. Wiknjosastro, 2007. Ilmu Kandungan.. Jakarta. Bina Pustaka Sarwono Prawirohardjo

11. Atika, Cahyo, 2010. Berat badan lahir rendah. Yogyakarta : Nuha Medika

12. Pantiawati, 2010. Bayi dengan berat badan lahir rendah. Yogyakarta : Nuha Medika

13. Rukiyah, 2010. Buku Saku : Mengenal Penyakit Melalui Hasil Pemeriksaan Laboratorium. Edisi Revisi. Yogyakarta : Amara Books

14. Marmi, Rahardjo, 2012. Asuhan Neonatus, Bayi, Balita, dan Anak Prasekolah. Yogyakarta : Pustaka Pelajar.

15. Lusmirasari. 2009. Pengaruh Perawatan Bayi Lekat Terhadap Pencapaian Pertumbuhan Bayi Berat Lahir Rendah.

16. Notoatmodjo, 2012. Metodologi Penelitian Kesehatan. Jakarta : Rineka Cipta 